\title{
Photovoltaic Characterization of Dye-sensitized Solar Cells with Natural Dyes using Synthesized ZnO nanostructures
}

\author{
I. B. Karki ${ }^{\text {* }}$, S. Chatterjee ${ }^{2}$, J. J. Nakarmi ${ }^{3}$, D. Sinha ${ }^{2}$, D. Goswami ${ }^{2}$ and P.K. Mandal \\ ${ }^{1}$ Department of Physics, Patan Multiple Campus, T. U., Lalitpur, ${ }^{2}$ Department of Physics, University of \\ North Bengal, Siliguri-734013, India, ${ }^{3}$ Central Department of Physics, Tribhuvan University, \\ Kathmandu, Nepal.E-mail:suman_chatterjee@hotmail.com
}

\begin{abstract}
Considerable attention was created over the past decade on Dye-sensitized solar cells (DSSCs) as a viable alternate technology for renewable energy. Much attention was attracted due to their high efficiencies and potentially low production costs. In this paper, DSSCs with natural dyes were successfully synthesized using $\mathrm{ZnO}$ nanostructures. ZnO nanorods were grown on an ITO coated glass using sol-gel method and used to fabricate DSSCs using natural dyes and liquid potassium iodide $\left(\mathrm{KI}_{3}\right)$ electrolyte. Different natural dye were analyzed for its suitability to be used in DSSC and subsequently used to fabricate the cell. Finally the photovoltaic properties of the ZnO based DSSC samples were systematically analyzed. Roles of new sensitizer dye were investigated and the results were compared. The ZnO nanorods grown by the sol-gel method have more uniform thickness. The DSSC structure with Carbon counter electrode yields an open circuit voltage markedly higher from DSSC on an ITO glass and has energy conversion efficiency less than $2 \%$.
\end{abstract}

Keywords: Dye-sensitized solar cells, Zinc Oxide Nanorods, Photovoltaic properties, Sol-gel method

\section{Introduction}

In recent years, great attention has been paid to Dye-sensitized solar cells (DSSCs) due to their low fabrication cost as a viable alternate technology for renewable energy ${ }^{1}$. It has attracted much attention due to their high efficiencies and their potentially low production costs. In this work we grew $\mathrm{ZnO}$ nanorods on a $\mathrm{ZnO}$ film using sol-gel technique. $\mathrm{ZnO}$ has shown a great deal of research interest in DSSCs due to some of its fascinating properties. $\mathrm{ZnO}$ is often utilized as a photoanode material in DSSCs due to its attractive properties such as large exciton binding energy, wide direct band gap (3.27 eV) equivalent to $\mathrm{TiO}_{2}$, which is generally used in organic solar cells ${ }^{1,2}$. $\mathrm{ZnO}$ is also highly transparent, which allows for greater light penetration. Finally, 1-D single crystal structure formation is possible with $\mathrm{ZnO}$, enabling a higher surface-to-volume ratio for greater dye loading.

DSSCs are a promising low cost, green energy source ${ }^{3,4}$. A power conversion efficiency of $11.18 \%$ has been achieved in $2005^{1}$. DSSC is a device for the conversion of visible light into electricity. The absorption spectrum of the dye and the anchorage of the dye to the surface of $\mathrm{ZnO}$ are important parameters determining the efficiency of the cell ${ }^{2}$.Generally, transition metal coordination compounds (ruthenium polypyridyl complexes) are used as the effective sensitizers, due to their intense chargetransfer absorption in the whole visible range and highly efficient metal-to ligand charge transfer ${ }^{3}$. However, ruthenium polypyridyl complexes contain a heavy metal, which is undesirable from point of view of the environmental aspects and high cost ${ }^{4}$.

\section{* Corresponding author}


Moreover, the process to synthesize the complexes is complicated and costly. Alternatively, natural dyes can be used for the same purpose with an acceptable efficiency ${ }^{5,6,7,8,9}$. The advantages of natural dyes include their availability and low $\operatorname{cost}^{6}$. The sensitization of wide bandgap semiconductors using natural pigments is usually ascribed to anthocyanins. This makes electron transfer from the anthocyanin molecule to the conduction band of $\mathrm{ZnO}^{3}$. As reported ${ }^{5,6}$, anthocyanins from various plants gave different sensitizing performances. However, there is not an acceptable explanation behind these results, so far.

In this study, DSSCs were prepared using natural dyes Rose Bengal, Bedana and Sea buckthorn as photo sensitizers, as these dye is abundant in tropical countries ${ }^{8,10},{ }^{11}$. Rose Bengal Indian origin dye is one of the best photo sensitizer for $\mathrm{ZnO}$ photoanode to date and is much cheaper than Ru-complex dyes ${ }^{8,12,13}$. It is in xanthene class which absorbs wide spectrum of solar energy ${ }^{8,14}$ and energetically matches the $\mathrm{ZnO}$ and usual KI- $\mathrm{I}_{2}$ redox couple ${ }^{15,16,17}$ for DSSCs applications. The absorption spectra of dyes were recorded using a UV-VIS spectrophotometer (Perkin Elmer Lamda-35 model UV-VIS). The efficiency of the DSSC solar cells related to dye structures is discussed. This would be useful information for selecting xanthane class dyes and also lead to the synthesis of dyes for DSSCs. The performance of DSSCs using the mixed Rose Bengal - Bedana dyes was also investigated ${ }^{12,14}$. Our hypothesis was that two xanthene having different absorption characteristics would give even more synergistic effect compared to the mixed xanthene-chlorophyll dye reported by B. Pradhan et al..$^{8}$ This is because xanthene has advantages over chlorophyll as DSSC sensitizer ${ }^{6}$.

To increase the conversion efficiency of $\mathrm{ZnO}$ nanorod-based DSSCs, it would be desirable to eliminate the interface between ITO and the $\mathrm{ZnO}$ nanorods. Replacing the ITO layer with a $\mathrm{ZnO}$ film could eliminate the heterogeneous interface. Furthermore, since $\mathrm{ZnO}$ is transparent to the whole visible spectrum, it is a good TCO material. Chen et al. have recently carried out this concept by growing $\mathrm{ZnO}$ nanorods on a $\mathrm{ZnO}$ film using a two-step method ${ }^{18}$. In this work we grew $\mathrm{ZnO}$ nanorods on a $\mathrm{ZnO}$ film using sol-gel technique. $\mathrm{ZnO}$ has shown a great deal of research interest in DSSCs due to some of its fascinating properties.

\section{Experimental Details}

\section{Preparation of $\mathrm{ZnO}$ nanorod and counter electrode}

Spin-coating is a simple method for preparing $\mathrm{ZnO}$ nanoseed from Zinc acetate solution. In this process, we prepared $5 \mathrm{mM}$ solution of Zinc acetate dehydrate, $\left(\mathrm{CH}_{3} \mathrm{COO}\right)_{2} \mathrm{Zn} .2 \mathrm{H}_{2} \mathrm{O}$, (98\% Merck) with distilled methanol. The solution was spun on indium tin oxide (ITO)-coated glass substrates at $1000 \mathrm{rpm}$ for 30s. The Zinc acetate solution is spread on a rotating substrate ${ }^{5,6}$. The substrates were heated to $350^{\circ} \mathrm{C}$ in conventional oven for $30 \mathrm{~min}$ to yield layers of $\mathrm{ZnO}$ islands with their (100) plane parallel to the substrate surface. After evaporation of solvent, a thin $\mathrm{ZnO}$ film was formed. Repeating above process is feasible, which can control the thickness of the film. Concentration of the solution and rotating rate of the substrate are also play important roles in adjusting the thickness of the formed film. This method can coat one side of conducting ITO coated on glass substrates. The counter electrode (cathode) is prepared on another ITO coated glass by using carbon dust. The molecular structure of used dye is given below Figure.1 .

\section{Dye Deposition}

The device was then immersed in a solution of sensitized dye Rose Bengal for 24 hours to allow the dye molecules to covalently bond to the surface of the $\mathrm{ZnO}$. The sample were then rinsed with ethanol to remove excess dye on the surface and air-dried at room temperature.

\section{DSSC assembling}


DSSCs were assembled following the procedure described in the literature ${ }^{7}$. The carbon dust coated counter electrode was placed on the top so that the conductive side of the counter electrode faces the $\mathrm{ZnO}$ film. The iodide based solution as the liquid electrolyte $(0.5 \mathrm{M}$ potassium iodide mixed with $0.05 \mathrm{M}$ iodine in water-free ethylene glycol) was placed at the edges of the plates. The liquid was drawn into the space between the electrodes by capillary action. Two binder clips were used to hold the electrodes together.<smiles>O=C1OC2(c3cc(I)c(O)c(I)c3Oc3c2cc(I)c(O)c3I)c2c(Cl)c(Cl)c(Cl)c(Cl)c21</smiles>

Figure1: Molecular structure of Rose Bengal (4,5,6,7-tetrachloro-2', 4', 5', $7^{\prime}-$

tetraiodofluorescein) and its formula $\mathrm{C}_{20} \mathrm{H}_{4} \mathrm{Cl}_{4} \mathrm{I}_{4} \mathrm{O}_{5}$ and molar mass $973.69 \mathrm{~g} \mathrm{~mol}^{-1}$.

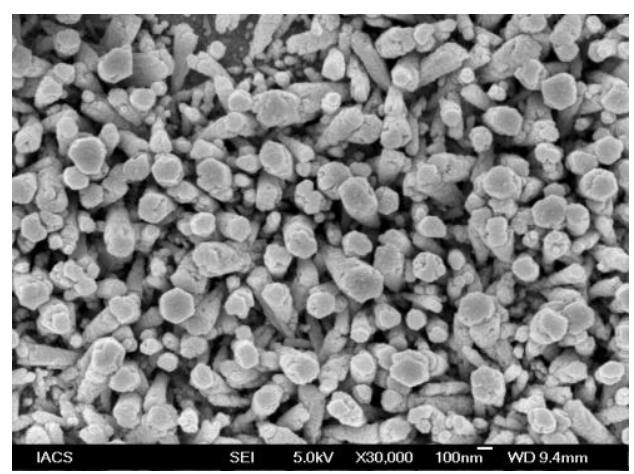

Figure 2: Scanning electron microscope (SEM) picture of $\mathrm{ZnO}$ nano tubes film grown on ITO coated glass plate used in the dye-sensitized solar cell

\section{Characterization and Measurement}

\section{Apparatus Setup}

An Oriel Xenon-lamp (450 Watt) used as the light source, and a Keithley model 2400 digital source pico-ammeter was employed to measure the dark-light and illuminated $I-V$ curves of the DSSC during the efficiency measurement experiments. The position of the light source was adjusted such that the light intensity is $100 \mathrm{~mW} / \mathrm{cm}^{2}$ (the equivalent of one sun) at AM 1.5 of power was delivered to the surface of the measured DSSC solar cell. The current-voltage characteristics of DSSCs under various light intensities were obtained. formula

The solar conversion efficiency $(\eta)$ of a DSSC can be estimated using the conversion efficiency

$$
\eta=P_{\max } / P_{i n}
$$

where $P_{\max }$ and $P_{\text {in }}$ denote the maximum output power and the input power, respectively. Since a DSSC usually contains a series resistance, $R_{\mathrm{S}}$ and a shunt resistance, $R_{s h}$, the fill factor (FF) is introduced to count both effects.

$$
\mathrm{FF}=\left(I_{\max } V_{\text {max }} / I_{s c} \times V_{o c},\right.
$$

where $V_{\mathrm{oc}}$ is the open-circuit voltage and $\mathrm{I}_{\mathrm{sc}}$ is the short-circuit current, $I_{\max }$ and $V_{\max }$ are the photocurrent and photo voltage for the maximum power output $\left(P_{\max }\right)$. The solar conversion efficiency of a DSSC can be calculated by 


$$
\eta=I_{\mathrm{sc}} \times V_{\mathrm{oc}} \times F F / P_{\text {in }}
$$

\section{Result and Discussion}

\section{Structure Characterization}

Figure 2 shows top view and SEM image of $\mathrm{ZnO}$ nanorods. The morphology of the samples was observed using a scanning electron microscope (SEM) with a field emission gun operating at $200 \mathrm{kV}$. The nanorods have an average length of $100 \mathrm{~nm}$, diameter ranging from 10 to $20 \mathrm{~nm}$ and they are mostly vertically aligned with the substrate. A $\mathrm{ZnO}$ film of thickness $\sim 2 \mu \mathrm{m}$ can be clearly seen.

\section{Photovoltaic Properties}

We have recorded $I-V$ characteristics of $\mathrm{ZnO}$ nanorods based DSSCs using Rose Bengal dye. Figure 3 shows the photocurrent - resistance characteristics for ZnO-nanorod DSSC at two different biasing condition $(0 \mathrm{~V}$ and $0.5 \mathrm{~V})$ with and without light. In general, the energy conversion efficiency of $\mathrm{ZnO}$ DSSCs is lower than that of $\mathrm{TiO}_{2}$ DSSCs. Note that the efficiency of ZnO-nanorod-based DSSCs with natural dyes is typically $1 \%-2 \%$.

\section{Conclusion}

In conclusion, we have demonstrated a new DSSCs structure with an ITO coated glass substrate. A $\mathrm{ZnO}$ nanorod grown by the sol-gel method. The $\mathrm{ZnO}$ nanorods grown by the sol-gel method have more uniform thickness. The DSSC structure yields an open circuit voltage markedly higher from DSSC on an ITO glass. We find that the efficiency of $\mathrm{ZnO}$ nanostructures based DSSCs is related to the various natural dyes. Higher electrical conductance in the $\mathrm{ZnO}$ film and appropriate dyes are needed to improve the DSSC efficiency.

We are confident that these types of fabrication at low cost can also improve efficiency performance of DSSCs by using liquid electrolyte $\mathrm{KI}_{3}$. A study of parasitic resistances parameters $\left(R_{s}\right.$ and $\left.R_{s h}\right)$ of DSSCs from I-V curve using the equivalent circuit one-diode model will be presented in a future paper.

\section{Acknowledgements}

The authors would like to address their thanks to the Central Department of Physics, Tribhuvan University, Kathmandu, North Bengal University, Darjeeling, Siliguri, University Grants Commission (UGC), Nepal National Academy of Science and Technology (NAST), Nepal, and Indian National Science Academy (INSA), India, for their financial and technical support for this work. 


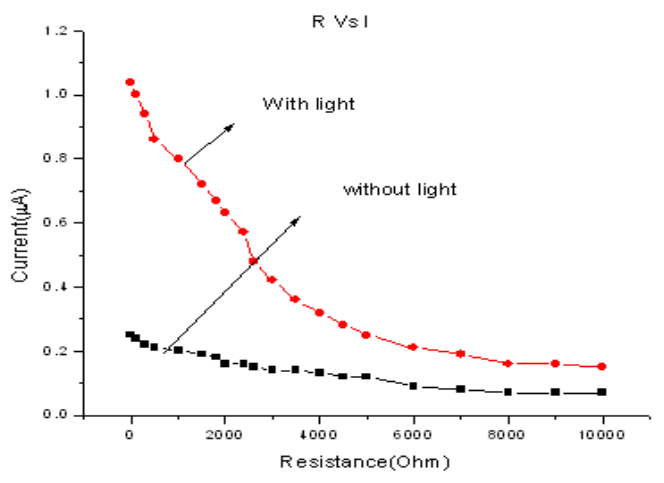

(a) Bias 0V:

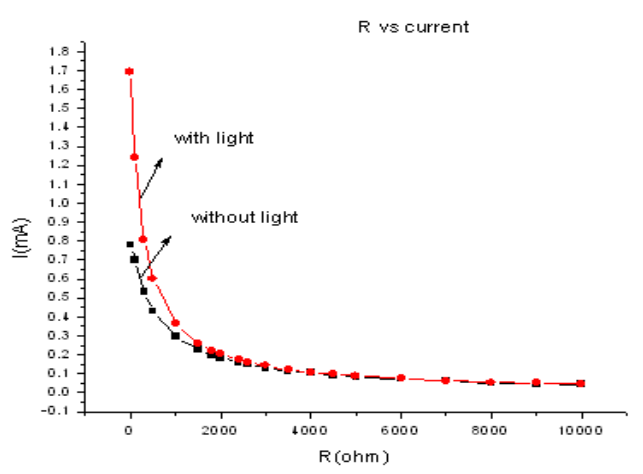

(b) $\underline{\text { Bias 0.5V }}$

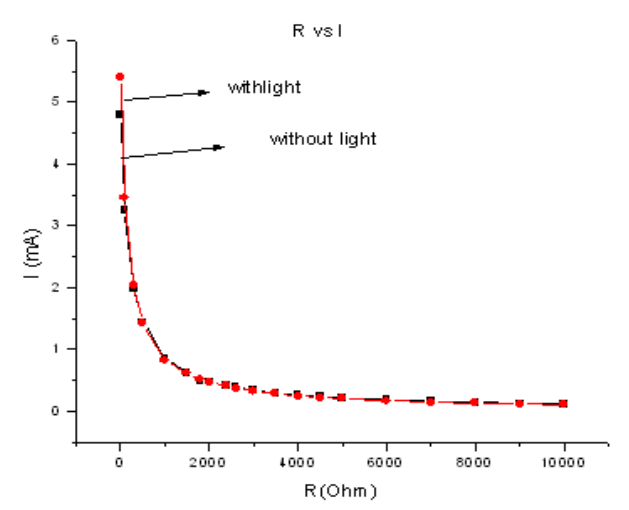

(c) Bias 1V:

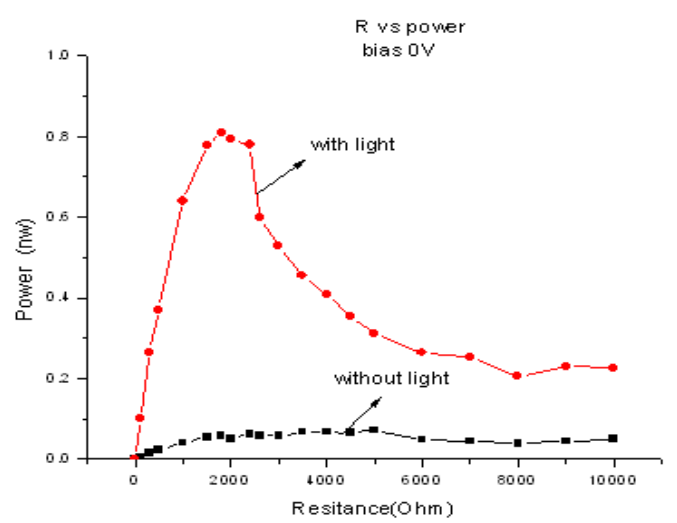

(a) Bias 0V:

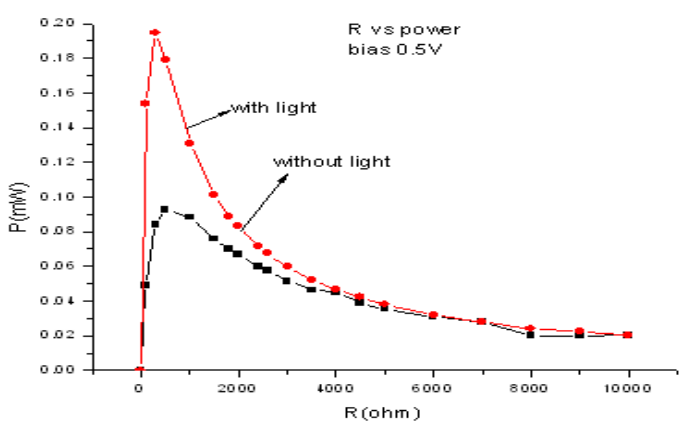

(b) $\underline{\text { Bias } 0.5 \mathrm{~V}}$

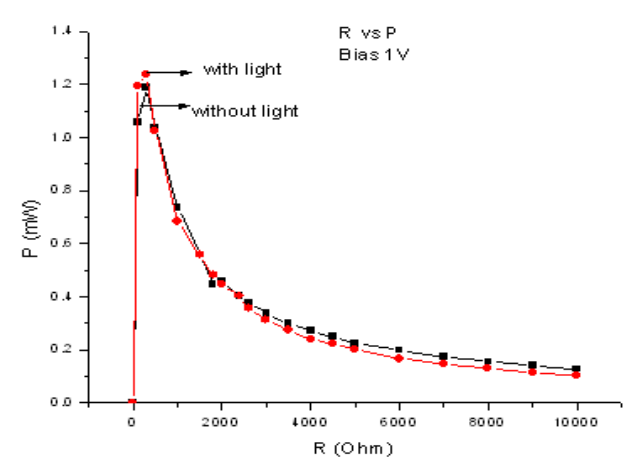

(c) $\underline{\text { Bias 1V: }}$

Figure 3: Current vs Load resistance with different biasing voltages 


\section{References}

1. M. Gratzel, J. Photochem. Photobiol., 2003, C4, 145

2. K. Tennakone, G.R.R.R.A. Kumara, A.R. Kumarasinghe, P.M.Sirimanne, K.G.U. Wijayantha, J. Photochem.Photobiol. A, 1996, 94, 217

3. S. Hao, J. Wu, Y. Huang, J. Lin, Sol. Energy 2006, 80, 209

4. Y. Amao, T. Komori, Biosensors Bioelectron. $2004,19,843$

5. A.S. Polo, N.Y. Iha, Sol. Energy Mater. Sol. Cells, 2006, 90, 1936

6. C.G. Garcia, A.S. Polo, N.Y. Iha, J. Photochem. Photobiol. A, 2003,160, 87

7. G.P. Smestad, Sol. Energy Mater. Sol. Cells, 1998, 55 ,157

8. B. Pradhan, S.Kumar, B. Amal, J. Pal, Sol. Energy Mater. Sol. Cells, 2007, 91, 769-773

9. N.J. Cherepy, G.P. Smestad, M. Gra“ tzel, J.Z. Zang, J. Phys. Chem. B , 1997, 101, 9342

10.T. Frank, J. Clin. Pharmacol., 2005, 45 ,203

11. N. Terahara, N. Saito, T. Honda, K. Tokis, Y. Osajima, Phytochemistry, , 1990, 29, 949

12. B. Pradhan, A. Bandyopadhyay, A. J. Pal, Appl Phys. Lett., 2004, 85, 663

13. A. Bandhopadhyay and A. J. Pal, J.Phys. Chem. B, 2003, 107, 2531-2536

14.H. Tsubomura, M. Matsumura, Y. Nomura, T. Amamiya, Nature, 1976, 261, 402

15. N.W. Duffy, L.M. Peter, R.M.G. Rajapakse, K.G.U. Wijayantha, J.Phys.chem. ,2000, 104 ,8916.

16. M. Graetzel, Nature, 2001, 114, 338-344

17. M. Law, Lori E. Greene, Justin C. Johnson, Richard Aykally and Peidong Yang. Nat. Mat. 2005, 4, 455-459.

18. H. Chen, A. Du Pasquier, G. Saraf, J. Zhong, and Y. Lu, Semiconductor Science and Technology, 2008, 23, 1-5. 
J. Nepal Chem. Soc., vol. 30, 2012

$-62-$ 